\title{
Selective Loss of Thin Spines in Area 7a of the Primate Intraparietal Sulcus Predicts Age-Related Working Memory Impairment
}

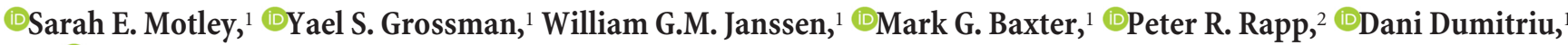 \\ and $\mathbb{\odot}^{\mathrm{J} o h n} \mathrm{H}$. Morrison ${ }^{1,3,4}$ \\ ${ }^{1}$ Department of Neuroscience and Friedman Brain Institute, Icahn School of Medicine at Mount Sinai, New York, New York 10029, ${ }^{2}$ Neurocognitive Aging \\ Section, National Institute of Aging, Baltimore, Maryland 21214, ${ }^{3}$ California National Primate Research Center, University of California-Davis, Davis, \\ California 95616, and ${ }^{4}$ Department of Neurology, School of Medicine, University of California-Davis, Sacramento, California 95817
}

Brodmann area $7 \mathrm{a}$ of the parietal cortex is active during working memory tasks in humans and nonhuman primates, but the composition and density of dendritic spines in area 7a and their relevance both to working memory and cognitive aging remain unexplored. Aged monkeys have impaired working memory, and we have previously shown that this age-induced cognitive impairment is partially mediated by a loss of thin spines in prefrontal cortex area 46 , a critical area for working memory. Because area 46 is reciprocally connected with area $7 \mathrm{a}$ of the parietal cortex and $7 \mathrm{a}$ mediates visual attention integration, we hypothesized that thin spine density in area $7 \mathrm{a}$ would correlate with working memory performance as well. To investigate the synaptic profile of area $7 \mathrm{a}$ and its relevance to working memory and cognitive aging, we investigated differences in spine type and density in layer III pyramidal cells of area 7a in young and aged, male and female rhesus macaques (Macaca mulatta) that were cognitively assessed using the delayed response test of working memory. Area 7 a shows age-related loss of thin spines, and thin spine density positively correlates with delayed response performance in aged monkeys. In contrast, these cells show no age-related changes in dendritic length or branching. These changes mirror age-related changes in area 46 but are distinct from other neocortical regions, such as V1. These findings support our hypothesis that cognitive aging is driven primarily by synaptic changes, and more specifically by changes in thin spines, in key association areas.

Key words: aging; area 7a; dendritic spines; primate; thin spines; working memory

Significance Statement

This study advances our understanding of cognitive aging by demonstrating the relevance of area 7a thin spines to working memory performance. This study is the first to look at cognitive aging in the intraparietal sulcus, and also the first to report spine or dendritic measures for area 7a in either young adult or aged nonhuman primates. These results contribute to the hypothesis that thin spines support working memory performance and confirm our prior observation that cognitive aging is driven by synaptic changes rather than changes in dendritic morphology or neuron death. Importantly, these data show that age-related working memory changes are not limited to disruptions of the prefrontal cortex but also include an association region heavily interconnected with prefrontal cortex.

\section{Introduction}

Brodmann area $7 \mathrm{a}$ of the parietal cortex is active during working memory tasks in humans (Pisella et al., 2004; Berryhill and Olson,
2008; Koenigs et al., 2009) and nonhuman primates (NHPs) (Quintana et al., 1989; Quintana and Fuster, 1992, 1993; Constantinidis and Steinmetz, 1996; Chafee and Goldman-Rakic, 2000). Although the electrophysiological properties of area $7 \mathrm{a}$

by the Intramural Research Program of the National Institute on Aging. We thank Anthony Santistevan for advice on linear mixed models.

The authors declare no competing financial interests.

Correspondence should be addressed to Dr. John H. Morrison, Department of Neurology, School of Medicine, University of California-Davis, One Shields Avenue, Davis, CA 95616. E-mail: jhmorrison@ucdavis.edu.

https://doi.org/10.1523/JNEUROSCl.1234-18.2018

Copyright $\odot 2018$ the authors $\quad 0270-6474 / 18 / 3810467-12 \$ 15.00 / 0$ 
pyramidal cells are well characterized (Constantinidis and Steinmetz, 1996; Rawley and Constantinidis, 2009; Qi et al., 2010), the composition and density of dendritic spines in area $7 \mathrm{a}$ and their relevance both to working memory and cognitive aging remain unexplored.

Working memory, the ability to retain information in mind in the absence of sensory stimuli (Goldman-Rakic, 1995), is highly vulnerable to aging in humans (Salthouse et al., 1991) and NHPs (Bartus et al., 1978; Rapp and Amaral, 1989; Bachevalier et al., 1991; Voytko and Tinkler, 2004). The delayed response (DR) task (Goldman-Rakic, 1990) is commonly used to assess working memory in NHPs. Critically, this task has a delay period during which the stimulus is absent and the monkey must retain taskrelevant information required for goal-directed behavior until the delay period ends.

During this delay period, aged NHPs have reduced persistent firing of delay cells in area 46 of the dorsolateral prefrontal cortex (dlPFC), and there is a direct relationship between DR performance and delay cell alterations in area 46 over the lifetime of the monkey (Wang et al., 2011). The dlPFC is a region highly involved in working memory (Luebke et al., 2010), and we have previously shown that thin spines are the predominant spine phenotype in area 46 (Dumitriu et al., 2010). It is proposed that thin spines contribute to working memory by allowing for rapid, experience-dependent circuit remodeling (Kasai et al., 2003; Arnsten et al., 2012). Aged NHPs have a specific loss of thin spines in area 46 that correlates with performance on a dlPFCdependent task (Dumitriu et al., 2010). There is no age-related neuron loss in area 46 (Peters et al., 1994), and no age-related changes are seen in dendritic length or arborization of locally projecting area 46 pyramidal cells (Kabaso et al., 2009). Thus, the substrate of age-related working memory impairments in area 46 appears to be a reduction in thin spines rather than a loss of pyramidal neurons or dendritic extent.

Area 46 has reciprocal connections with area $7 \mathrm{a}$ (Cavada and Goldman-Rakic, 1989b), and these two regions are coactive during working memory tasks (Friedman and Goldman-Rakic, 1994). Cooling a portion of the parietal cortex that includes area 7 a during the DR task significantly alters neuronal firing in the dIPFC and increases DR reaction times (Quintana et al., 1989; Quintana and Fuster, 1993; Chafee and Goldman-Rakic, 2000). This led us to hypothesize that age-related synaptic changes in area 7 a could contribute to age-related working memory impairments via the reciprocal connections between areas $7 \mathrm{a}$ and 46 . Because thin spines predominate area 46 (Dumitriu et al., 2010) and are proposed to play an important role in working memory (Kasai et al., 2003; Arnsten et al., 2012), we hypothesized that thin spines would be the dominant spine phenotype in area $7 \mathrm{a}$ and that thin spine density would positively correlate with working memory performance. To address these hypotheses, we microinjected and imaged individual layer III pyramidal neurons in fixed sections from area $7 \mathrm{a}$ of young and aged, male and female rhesus macaques (Macaca mulatta) that had been behaviorally tested on the DR task. We examined the density and size distribution of dendritic spines, as well as the total length and branching of the dendritic arborization. Consistent with our hypothesis, aged monkeys showed a decrease in overall spine density due to a specific loss of thin spines. Importantly, thin spine density positively correlated with behavioral performance. In contrast, no differences were seen between young and aged monkeys in dendritic length or arborization, supporting our hypothesis that cognitive aging is driven by synaptic changes (Morrison and Baxter, 2012, 2014).

\section{Materials and Methods}

\section{Monkeys}

All experiments were conducted in compliance with the National Institutes of Health Guidelines for the Care and Use of Experimental Monkeys under protocols approved by the Institutional Monkey Care and Use Committees at the University of California-Davis and the Icahn School of Medicine at Mount Sinai.

Six young adult (age range, $6-13.4$ years, mean \pm SD, $9.6 \pm 2.4$ years old; 5 females, 1 male) and 12 aged (age range, $21-34.7$ years, mean $\pm S D$, $26.6 \pm 4.7$ years old; 11 females, 1 male) Rhesus macaques (M. mulatta) were included in this study. Monkeys were part of a larger cohort that had been previously tested on a DR task (Dumitriu et al., 2010; Young et al., 2014). To study the effects of cognitive aging, monkeys were selected for inclusion in this study based on their DR average performance. The 6 aged monkeys with the best average DR performance (DR average range, $72.7 \%-87.6 \%$, mean $\pm \mathrm{SD}, 78.3 \pm 6.1 \%$; age range, $21-32.9$ years old, mean \pm SD, $27.9 \pm 4.7$ years old; 5 females, 1 male) and the 6 aged monkeys with the worst average DR performance (DR average range, $57.8 \%-69.8 \%$, mean $\pm \mathrm{SD}, 62.3 \pm 4.9 \%$; age range, $22-34.7$ years old, mean \pm SD, $25.2 \pm 4.7$ years old; 6 females) were selected to be compared against 6 young monkeys (DR average range $77.1 \%-90.2 \%$, mean \pm SD $80.3 \pm 5.1 \%$; age range, $6-13.4$ years, mean \pm SD, $9.6 \pm 2.4$ years old; 5 females, 1 male). Behavioral results were previously reported (Dumitriu et al., 2010; Hara et al., 2014, 2016; Young et al., 2014).

The 18 monkeys chosen for this study were part of a larger group of monkeys that were behaviorally tested on several tasks, using identical test protocols and apparatus, spanning 18 years. This population included 34 young monkeys and 72 aged monkeys (P.R.R., unpublished data). The monkeys analyzed in the present study were representative of the population as a whole. Of 34 young monkeys, the 6 young monkeys included here ranked 7th, 11th, 13th, 14th, 18th, and 26th in average delay performance on the DR task, with a mean rank of 14.8. Of 72 aged monkeys, the 18 aged monkeys included here were ranked $3 \mathrm{rd}$, 4th, 5th, 15th, 16th, 26th, 39.5th, 44th, 52nd, 56th, 63rd, and 70th in average delay performance on the DR task, with a mean rank of 32.8. The average rank of age unimpaired (AU) monkeys was 11.5, and the average rank of age impaired (AI) monkeys was 54.3. In our tissue bank, tissue was available from 8 young and 20 aged monkeys. The top 6 aged performers were selected for our aged AU group, and the bottom 6 aged performers were selected for our aged AI group.

\section{Behavioral testing}

Delayed response $(D R)$. Spatiotemporal working memory was tested using the DR task in an equivalent approach as our prior studies (Rapp et al., 2003; Hao et al., 2007). Monkeys watched from behind a transparent screen while the experimenter baited one of two wells with a food reward and then covered both wells with identical opaque covers. During the training phase, the transparent screen was immediately raised and the monkey was allowed to retrieve the food reward by displacing one of the opaque covers. The monkey was not permitted to displace the second cover if it first incorrectly chose the nonbaited well. The left/right position of the reward was pseudorandomly balanced across trials. Training continued until the monkey reached criterion, defined as correctly choosing the baited well for $\geq 90 \%$ of the trials across nine consecutive blocks of 10 trials/block (30 trials/d). During the testing phase, a delay was introduced before the monkey was permitted to respond, enforced by lowering an opaque screen so the monkey could not view the wells. In this manner, removal of sensory input about the stimulus during the delay period probed working memory. Initially a $1 \mathrm{~s}$ delay was imposed; and once the monkey reattained criterion ( $\geq 90 \%$ over 90 trials), the working memory demands were increased with successively longer delay periods. Delay intervals of $5,10,15,30$, and $60 \mathrm{~s}$ were each tested for 90 trials ( 450 trials total, 30 trials/d; $20 \mathrm{~s}$ intertrial interval). Average DR performance was calculated as the average performance across the delay intervals of 5-60 s (5 delay intervals, 90 trials/delay interval). Average DR performance was used as the selection criterion for inclusion in this study.

Delayed nonmatching to sample (DNMS). Visual recognition memory was tested using the DNMS task in an equivalent approach as our prior 
studies (Rapp and Amaral, 1991; Rapp et al., 2003). The experimenter baited a central well with a food reward behind an opaque screen, out of view of the monkey. After the well was baited, the opaque screen was lifted and the monkey was presented with a single sample object over the baited central well. The monkey was allowed to retrieve the food reward by displacing the sample object. After the monkey retrieved the food reward, a delay interval was imposed by lowering the opaque screen so the monkey could not see the wells. During the delay interval, the experimenter baited one well with a food reward and covered it with a novel object. A second well was left unbaited and was covered with the previously seen sample object. Objects were selected from a large pool such that the pairs presented were trial-unique. At the end of the delay interval, the opaque screen was raised and the monkey was presented with the two objects simultaneously (the previously seen sample object and the paired novel object) and permitted to uncover one well. The correct choice was to choose the novel, rewarded object. During the acquisition phase, a $10 \mathrm{~s}$ delay interval was imposed. Once the monkey had reached criterion ( $\geq 90 \%$ over 100 trials, 20 trials/d, 30 s intertrial interval), then successively longer delay intervals were imposed. Delay intervals of 15 , 30,60 , and $120 \mathrm{~s}$ were each tested for 100 trials (400 trials total, 20 trials/d), and the final delay period of $600 \mathrm{~s}$ was tested for 50 trials (5 trials/d). Average DNMS performance was calculated as the average performance across the delay intervals of 15-600 s.

Object discrimination $(O D)$. Visual discrimination was tested using the OD task in an equivalent approach as our prior studies (Rapp et al., 2003). From behind an opaque screen, the experimenter placed two objects on the testing board, one object per well. After the objects were placed, the opaque screen was lifted and the monkey was presented with the object pair. For each discrimination pair, a single object was consistently rewarded while the other object was never rewarded. For the first encounter with each problem, both wells were unbaited for a single, unscored "pretrial" and the monkey was permitted to choose one object. The object that the monkey did not choose on the "pretrial" was the rewarded object for the remainder of the trials for that discrimination pair. This procedure was intended to avoid reinforcing innate object preferences. During subsequent testing, a delay was introduced between each trial, enforced by lowering an opaque screen so the monkey could not view the wells. Four discrimination pairs were tested $(30$ trials $/ \mathrm{d}, 15 \mathrm{~s}$ intertrial interval). The left/right position of the rewarded object was pseudorandomly balanced across trials, and the order of pairs was fixed across monkeys. Testing occurred on day 1, $24 \mathrm{~h}$ later on day 2 , and $48 \mathrm{~h}$ later on day 4 . Average OD performance was calculated as the average performance across the 3 testing days.

\section{Perfusion and tissue processing}

All monkeys completed DR, DNMS, and OD testing, in that order. After the completion of behavioral testing, some monkeys engaged in other behavioral testing until the time of perfusion. If perfusion was not scheduled on the day immediately following the last day of behavioral testing, then the monkey continued with mock training trials (DNMS trials with short delays) until the day before perfusion to avoid variability in any testing-induced alterations in synaptic structure.

Monkeys were deeply anesthetized with ketamine hydrochloride (25 $\mathrm{mg} / \mathrm{kg}$ ) and sodium pentobarbital (20-35 mg/kg, i.v.), intubated, and mechanically ventilated. The descending aorta was clamped immediately after intubation, and sodium nitrate $(0.5 \%, 1.5 \mathrm{ml})$ was injected into the left ventricle of the heart to increase vasodilation. Perfusion was performed with cold 1\% PFA in $0.1 \mathrm{~m}$ phosphate buffer, $\mathrm{pH} 7.2$, for $2 \mathrm{~min}$ $(250 \mathrm{ml} / \mathrm{min})$, followed by $4 \%$ PFA in $0.1 \mathrm{~m}$ phosphate buffer, $\mathrm{pH} 7.2$, for $10 \mathrm{~min}(250 \mathrm{ml} / \mathrm{min})$. The flow rate was then reduced to $100 \mathrm{ml} / \mathrm{min}$ and continued to perfuse for $50 \mathrm{~min}$.

After perfusion, the brain was removed from the skull and dissected into standardized blocks. Blocks were postfixed in 4\% PFA with $0.125 \%$ glutaraldehyde in phosphate buffer for $6 \mathrm{~h}$. The parietal block of the right hemisphere, containing area $7 \mathrm{a}$, was kept in $0.1 \mathrm{~m}$ PBS with $0.1 \%$ sodium azide until the initiation of this study, at which time it was serially sectioned on a Vibratome (Leica Microsystems VT1000S) into a systematic series of $300-\mu \mathrm{m}$-thick sections. The posterior sections were collected for intracellular injections.

\section{Intracellular injections}

Intracellular injection of layer III pyramidal neurons with AlexaFluor568 hydrazide (Invitrogen) was performed according to previously published methods (Hao et al., 2006, 2007; Dumitriu et al., 2010, 2011; Ohm et al., 2012; Young et al., 2014). Briefly, $300 \mu \mathrm{m}$ sections were counterstained with DAPI to permit visualization of the somata using epifluorescence under a UV filter. Sections were mounted on filter paper and immersed in $0.1 \mathrm{M}$ PBS. Layer III pyramidal neurons were identified, impaled with sharp micropipettes, and filled with AlexaFluor-568 hydrazide for 3-5 min using 1-20 nA direct current. All filled neurons had somata located in layer III and within the boundaries of area 7a. Approximately 6-10 neurons were microinjected per section, spaced sufficiently apart so that dendritic arbors did not overlap. One to three sections were used per monkey, representing a random sampling of neurons throughout posterior area 7a. Sections were mounted on glass slides with VectaShield mounting medium (Vector Laboratories) and covered with number 1.5 cover glass (Corning).

Imaging and quantitative analyses of spine density and spine size All 18 monkeys (6 per group) were included in the quantitative spine analysis, and included segments were completely filled as evidenced by their well-defined endings. No incomplete segments were included in the study. Twenty apical and 20 basal segments were sampled per monkey, with no more than three segments taken from the same neuron. A confocal tile image of the section was taken at $10 \times$ magnification to create a neuron map. A confocal $z$ stack image of each neuron was taken at $20 \times$ magnification that was then used for unbiased but systematic selection of segments to be imaged at high resolution. These neuron map images were intentionally low resolution such that segments, but not spines, were visible, so as not to bias the experimenter in the choice of segments to be imaged at high magnification. Concentric rings were drawn around the soma at $50 \mu \mathrm{m}$ intervals. Secondary or tertiary basal segments were sampled if they crossed at $50 \mu \mathrm{m}$ from the soma, and secondary or tertiary apical segments were sampled if they crossed between 50 and 100 $\mu \mathrm{m}$ from the soma. Confocal $z$ stack images of each segment were taken at $100 \times$ magnification on an upright LSM780 (Carl Zeiss) to generate the image used for spine analysis. Confocal $z$ stacks of 100-300 images were acquired with an $x, y$ resolution of $0.07 \mu \mathrm{m}$ and a $z$ step of $0.1 \mu \mathrm{m}$ using a Plan-Apochromat $100 \times / 1.4$ NA oil-immersion objective (Carl Zeiss). All $z$ stacks included at least $1 \mu \mathrm{m}$ above the most superficial spine and 1 $\mu \mathrm{m}$ below the deepest spine to ensure that all spines were completely imaged. AlexaFluor-568 was excited with a solid-state DPSS $561 \mathrm{~nm}$ laser with $2 \%$ laser power with a pinhole size of 0.85 Airy units (AU)/79 $\mu \mathrm{m}$, with an emission filter of $568-712 \mathrm{~nm}$, a digital zoom of 2.4, an averaging of 2, and a pixel dwell time of $1.58 \mu \mathrm{s}$. The final resolution of the $z$ stacks was $512 \times 512$ pixels. The precise distance from soma for each segment was measured, and this intersection was used as the starting point for each imaged segment. The length of each segment imaged was determined by the parameters of $x, y$ pixel resolution $(512 \times 512$ pixels $)$, the magnification $(100 \times)$, and the digital zoom $(2.4 \times)$, resulting in an FOV that was $35.8 \mu \mathrm{m}$ in length. One FOV $(35.8 \mu \mathrm{m})$ of each segment was imaged, starting at the appropriate distance from soma. The exact length of each segment included was between 35 and $50 \mu \mathrm{m}$, depending on the curvature of the segment in the field of view. Digital gain was set to 1 , and digital offset was set to 1.3. To achieve the best signal possible, the gain was set to maximize the dynamic range such that, for a given segment, there were only a few pixels of maximum signal intensity on one spine and only a few pixels of minimum signal intensity in the FOV. Master gain ranged from 480 to $750 \mathrm{~V}$. Our prior work has used the dye Lucifer yellow instead of AlexaFluor-568 for iontophoretic injection (Dumitriu et al., 2010; Young et al., 2014). To compare these results to our previous work, the pinhole size used here was chosen to achieve the same absolute resolution as the Lucifer yellow data, which was imaged with $488 \mathrm{~nm}$ excitation. The pinhole size used here was $79 \mu \mathrm{m}$, which yields a $0.85 \mathrm{AU}$ resolution for imaging at $568 \mathrm{~nm}$. This is the same pinhole size used for the Lucifer yellow data, where $79 \mu \mathrm{m}$ yields a $1 \mathrm{AU}$ resolution for imaging at $488 \mathrm{~nm}$. Previously, we have shown that decreasing the pinhole size $<1.0 \mathrm{AU}$ can improve the imaging resolution by decreasing the amount of scattered light that reaches the detector (Dumitriu et al., 2011). 


\section{DR Average Performance}

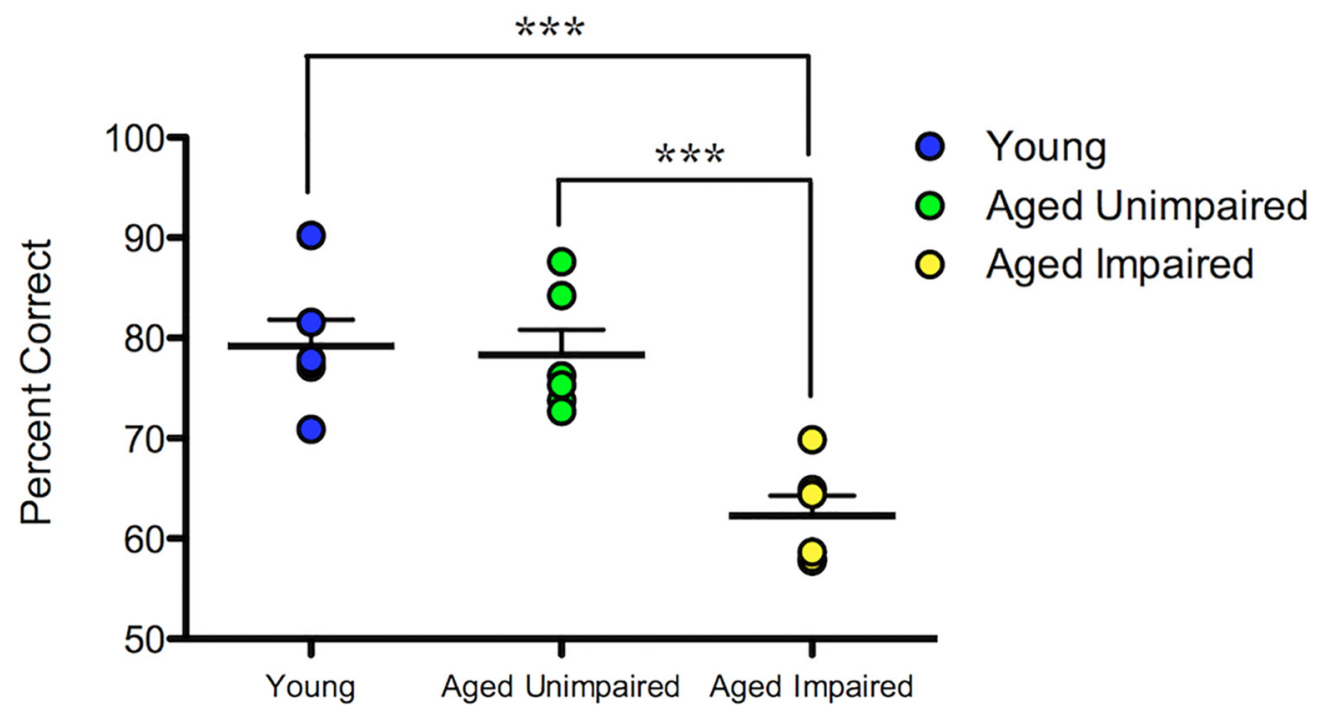

Figure 1. DR performance is impaired in a subset of aged monkeys. AU monkeys performed at levels similar to young controls, whereas Al monkeys performed significantly worse than both young and AU monkeys. ${ }^{* * *} p<0.001$.

Images were deconvolved with AutoQuant X3 (Media Cybernetics) and exported to Neurolucida 360 (MBF Bioscience) for 3D detection of spines. The measurements of spine head volume were automatically detected by Neurolucida 360 . All spine measurements (total 15,482 spines) were performed in 3D from the $z$ stacks. Neurolucida 360 generated .DAT files with 3D tracings of the segment and spines. The .DAT files were imported to Neurolucida Explorer (MBF Bioscience), which created .TXT files with numerical values for morphometric properties of each spine. The .TXT files were then imported into MATLAB (The MathWorks) for spine classification. Consistent with prior studies (Dumitriu et al., 2010) and with serial section EM reconstruction of dendritic segments (Sorra and Harris, 2000), spines were classified as thin if the head was $<0.6 \mu \mathrm{m}$ and the maximum length was at least twice the head diameter. Spines were classified as mushroom if the head diameter was $>0.6$ $\mu \mathrm{m}$. The remaining spines were classified as other, and presumably this group contains mostly stubby spines. The density for each segment was calculated as the total number of spines on a given segment divided by the segment length.

\section{Imaging and quantitative analyses of dendritic length and branching}

Due to neurons with cut segments because of variations in the orientation of tissue sectioning leading to truncated dendritic segments, only 3 monkeys from each group were included in the imaging and quantitative analyses of dendritic arborization for a total of 9 monkeys. Included neurons had completely filled dendritic arbors as evidenced by their well-defined endings. Six to eight neurons were traced per monkey. From the 3 young monkeys, we traced 18 complete whole neuron trees, 23 complete basal trees, and 19 complete apical trees. From the AU monkeys, we traced 15 complete whole neuron trees, 19 complete basal trees, and 19 complete apical trees. From the AI monkeys, we traced 20 complete whole neuron trees, 22 complete basal trees, and 21 complete apical trees. Tracings of the dendritic arborization were made from live images taken on Imager.M2 (Carl Zeiss). Neurons were located on a $10 \times$ objective and were illuminated with an X-Cite Series 120 Q (Lumen Dynamics). Once located, neurons were traced on a Plan-Apochromat $40 \times / 1.3$ oil-immersion objective (Carl Zeiss) using Neurolucida (MBF Bioscience). A live image of the neuron was fed into Neurolucida where the experimenter created a 3D tracing of the neuron superimposed on the live image by first drawing the soma and axon followed by the apical and basal dendrites. Neurolucida recorded the $x, y$, and $z$ positions of each point drawn by the experimenter. The $3 \mathrm{D}$ tracing of the neuron was saved as a .DAT file and imported into Neurolucida Explorer, which created.TXT files with numerical values for dendritic length and branching of each neuron.

\section{Experimental design and statistical analysis}

Statistical analyses were performed in MATLAB version 2014a (Mathworks) or R version 3.5.0 (R Core Team, 2018). For comparisons between young, $\mathrm{AU}$, and $\mathrm{AI}$ monkeys, a one-way ANOVA was performed followed by post hoc Bonferronicorrected contrasts. To examine the relationship between spine density and behavioral performance, linear mixed models using packages lme4 (Bates et al., 2015) and lmerTest (Kuznetsova et al., 2017) in R were calculated to predict spine measurements from behavioral performance (DR, DNMS, or OD), with age group (young or aged) and dendritic origin (apical or basal) as fixed factors, and monkey, slide, and neuron as random factors, thus considering age, spine density, and behavioral performance simultaneously. Of the 720 observations, one spine density measurement for one of the young monkeys was a statistical outlier ( $>4$ interquartile ranges $>3 \mathrm{rd}$ quartile of total spine density), so we excluded that observation from the model. Linear mixed models residual diagnostics were examined with the R package DHARMa (Hartig, 2018), and no violations of assumptions of the fitted model were observed. To compare the distribution of spine head volume, a two-sample Kolmogorov-Smirnov test was performed followed by post hoc Bonferroni-corrected multiple comparisons. The statistical significance value for all analyses was set at $p=0.05$. Values are shown as mean \pm SEM. Group values were calculated from one aggregate (mean) value per monkey.

\section{Results}

\section{DR behavioral performance}

As anticipated on the basis of the inclusion criteria used, AI monkeys performed significantly worse than AU monkeys or young monkeys, but there was no significant difference in DR performance between $\mathrm{AU}$ monkeys and young monkeys $\left(F_{(2,15)}=\right.$ 15.95, $p=2.0 \times 10^{-4}$, one-way ANOVA; AI vs AU: $p=7.0 \times$ $10^{-4}$; AI vs young: $p=4.0 \times 10^{-4}$; $\mathrm{AU}$ vs young: $p=0.96$, Bonferroni multiple comparison tests; Fig. 1; Table 1). These results support our selection criterion and classification for AU and AI monkeys. No differences were observed between groups 
Table 1. Behavioral performance from young, aged unimpaired, and aged impaired animals, and morphological measures of dendritic spines from area 7a layer III pyramidal cells from young, aged unimpaired, and aged impaired animals

\begin{tabular}{|c|c|c|c|c|c|c|}
\hline \multirow[b]{2}{*}{ Parameter } & \multicolumn{2}{|c|}{ Young } & \multicolumn{2}{|c|}{ Aged unimpaired } & \multicolumn{2}{|c|}{ Aged impaired } \\
\hline & Mean $\pm S D$ & Range & Mean $\pm S D$ & Range & Mean $\pm S D$ & Range \\
\hline \multicolumn{7}{|c|}{ Behavioral performance (\% correct) } \\
\hline DR average & $79.2 \pm 6.4$ & $70.9-90.2$ & $78.3 \pm 6.1$ & $72.7-87.6$ & $62.3 \pm 6.1$ & $57.7-69.8$ \\
\hline DR TCO & $76.7 \pm 67.1$ & $0-140$ & $121.7 \pm 122.7$ & $0-330$ & $185.2 \pm 197.3$ & $0-410$ \\
\hline DR TC 1 & $156.3 \pm 183.8$ & $0-478$ & $57.3 \pm 65.6$ & $0-134$ & $588.7 \pm 615.4$ & $20-1697$ \\
\hline DNMS average & $88.3 \pm 3.8$ & $81.9-92.4$ & $78.4 \pm 3.8$ & $73.0-84.4$ & $77.4 \pm 2.7$ & $73.8-80.4$ \\
\hline OD average & $91.9 \pm 1.8$ & $90.5-95.0$ & $87.4 \pm 4.1$ & $81.4-94.9$ & $83.6 \pm 9.6$ & $68.3-96.1$ \\
\hline$\overline{\text { Spine density (spines } / \mu \mathrm{m})}$ & \multicolumn{2}{|c|}{ Mean \pm SEM } & \multicolumn{2}{|c|}{ Mean \pm SEM } & \multicolumn{2}{|c|}{ Mean \pm SEM } \\
\hline Total & $0.6965 \pm 0.0349$ & $0.5724-0.8332$ & $0.5766 \pm 0.0161$ & $0.5168-0.6276$ & $0.4714 \pm 0.0397$ & $0.3597-0.6411$ \\
\hline Mushroom & $0.0477 \pm 0.0058$ & $0.0285-0.0683$ & $0.0773 \pm 0.0057$ & $0.0546-0.0935$ & $0.0539 \pm 0.0093$ & $0.0200-0.0781$ \\
\hline Thin & $0.5766 \pm 0.0308$ & $0.4532-0.6794$ & $0.4356 \pm 0.0184$ & $0.3700-0.5021$ & $0.3684 \pm 0.0355$ & $0.2664-0.5159$ \\
\hline \multicolumn{7}{|l|}{ Spine head volume $\left(\mu \mathrm{m}^{3}\right)$} \\
\hline Total & $0.1964 \pm 0.0051$ & $0.1879-0.2206$ & $0.2547 \pm 0.0156$ & $0.1982-0.3015$ & $0.2485 \pm 0.0199$ & $0.1565-0.2906$ \\
\hline Mushroom & $0.3828 \pm 0.0154$ & $0.3342-0.4500$ & $0.4762 \pm 0.0404$ & $0.3602-0.5871$ & $0.4224 \pm 0.0472$ & $0.2581-0.6089$ \\
\hline Thin & $0.1896 \pm 0.0047$ & $0.1773-0.2081$ & $0.2290 \pm 0.0106$ & $0.1879-0.2635$ & $0.2345 \pm 0.0163$ & $0.1608-0.2799$ \\
\hline \multicolumn{7}{|l|}{ Dendritic length $(\mu \mathrm{m})$} \\
\hline Total & $6037.0 \pm 524.5$ & $5445.7-7083.00$ & $5419.9 \pm 300.6$ & $4973.9-5992.1$ & $5837.9 \pm 367.2$ & $5147.4-6399.8$ \\
\hline Basal & $3462.5 \pm 375.9$ & $2913.7-4182.0$ & $2997.1 \pm 153.6$ & $2842.0-3304.2$ & $3366.7 \pm 232.2$ & $3038.0-3815.2$ \\
\hline Apical & $2222.1 \pm 160.0$ & $1903.1-2404.0$ & $2445.9 \pm 63.0$ & $2364.4-2569.8$ & $2474.3 \pm 327.2$ & $1839.2-2928.6$ \\
\hline \multicolumn{7}{|l|}{ Dendritic branching (nodes) } \\
\hline Total & $45.2 \pm 4.9$ & $46.9-63.6$ & $48.6 \pm 2.7$ & $43.5-52.8$ & $52.1 \pm 1.7$ & $49.2-55.0$ \\
\hline Basal & $30.3 \pm 2.8$ & $26.8-35.9$ & $26.8 \pm 1.2$ & $24.7-28.7$ & $30.0 \pm 1.9$ & $26.3-32.7$ \\
\hline Apical & $20.6 \pm 1.1$ & $18.5-22.3$ & $22.0 \pm 1.0$ & $20.1-23.3$ & $24.5 \pm 2.1$ & $18.7-26.0$ \\
\hline
\end{tabular}
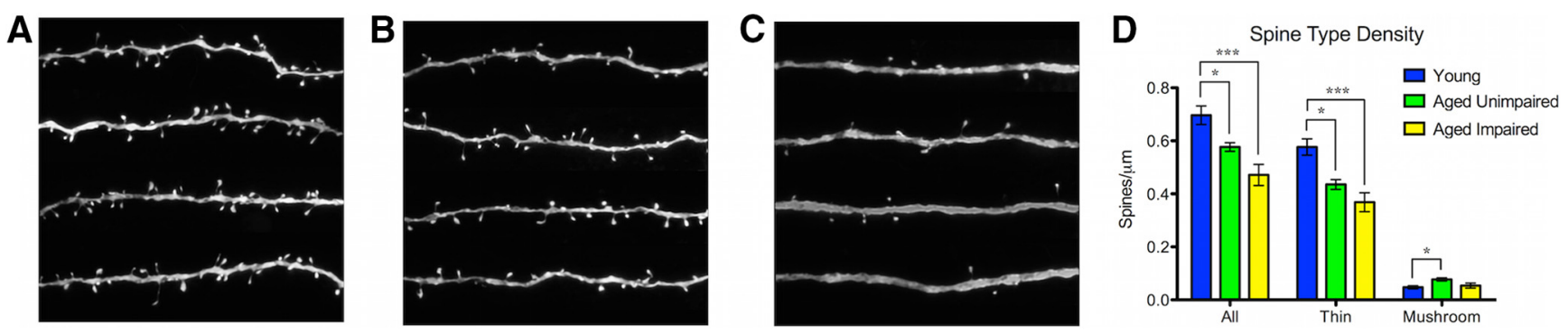

Figure 2. Age-related dendritic spine loss in area 7a. $\boldsymbol{A}-\boldsymbol{C}$, Representative dendritic segments from young $(\boldsymbol{A})$, AU (B), and AI ( $\boldsymbol{C}$ ) animals. $\boldsymbol{D}$, Al monkeys had a greater loss of total spines than $\mathrm{AU}$ monkeys compared with young monkeys. Al monkeys had a greater loss of thin spines than AU monkeys compared with young monkeys. AU monkeys had a significantly higher mushroom spine density than young monkeys. ${ }^{*} p<0.05 .{ }^{* * *} p<0.001$.

in acquisition of the DR behavioral task at either the $0 \mathrm{~s}$ or the $1 \mathrm{~s}$ delay $\left(0\right.$ s delay: $F_{(2,15)}=0.91, p=0.42 ; 1$ s delay: $F_{(2,15)}=3.45$, $p=0.06$, one-way ANOVA; Table 1).

\section{DNMS behavioral performance}

Because monkeys were selected for inclusion in this study based on DR performance, we did not anticipate any differences between AU and AI on DNMS performance. However, prior work has shown that aged monkeys perform significantly worse than young controls on DNMS (Dumitriu et al., 2010; Young et al., 2014); and consistent with those results, we found that both aged groups performed significantly worse than young controls $\left(F_{(2,15)}=\right.$ $18.12, p=1.0 \times 10^{-6}$, one-way ANOVA; AI vs young: $p=1.9 \times$ $10^{-4}$, AU vs young: $p=4.8 \times 10^{-4}$, AI vs AU: $p=0.88$, Bonferroni multiple comparison tests; Table 1).

\section{OD behavioral performance}

Prior work has shown no statistically reliable age-related differences in the performance of OD (Rapp, 1990, 1993). Consistent with those results, no differences were observed between groups in OD performance $\left(F_{(2,15)}=2.74, p=0.10\right.$, one-way ANOVA; Table 1).
Effects of aging on spine density in area 7a

Both AI and AU monkeys had a significant loss of total dendritic spines in area 7a. However, although not statistically significant, the magnitude of spine loss was higher in AI monkeys compared with AU monkeys $\left(F_{(2,15)}=12.45, p=7.0 \times 10^{-4}\right.$, one-way ANOVA; AI vs young: $p=5.0 \times 10^{-4}$, AU vs young: $p=0.04$, AI vs AU: $p=0.08$, Bonferroni multiple comparison tests; Fig. 2; Table 1). This overall age-related spine loss was driven entirely by a loss of thin spines, which also showed a higher magnitude, though nonstatistically significant, spine loss in AI compared with AU monkeys $\left(F_{(2,15)}=13.29, p=5.0 \times 10^{-4}\right.$, one-way ANOVA; AI vs young: $p=4.0 \times 10^{-4}$, AU vs young: $p=0.01, \mathrm{AI}$ vs $\mathrm{AU}: p=0.25$, Bonferroni multiple comparison tests; Fig. 2; Table 1). Interestingly, mushroom spines showed a very different pattern, with AU monkeys having significantly greater mushroom spine density compared with young monkeys, and no observed difference between $\mathrm{AI}$ and either the young or AU groups $\left(F_{(2,15)}=4.82, p=0.02\right.$, one-way ANOVA; AU vs young: $p=$ 0.03 , AI vs young: $p=0.81$, AI vs AU: $p=0.08$, Bonferroni multiple comparison tests; Fig. 2; Table 1). When basal or apical spines were analyzed separately, the same patterns were seen as when all spines were analyzed together (data not shown). 
A All Spine Density v. DR Average Performance

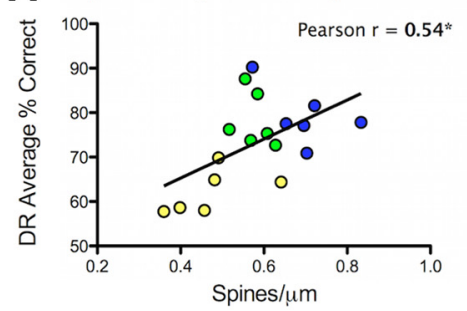

B Thin Spine Density v. DR Average Performance

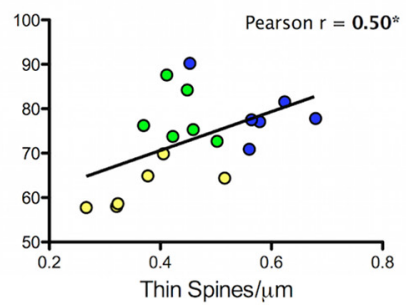

C Mushroom Spine Density v. DR Average Performance

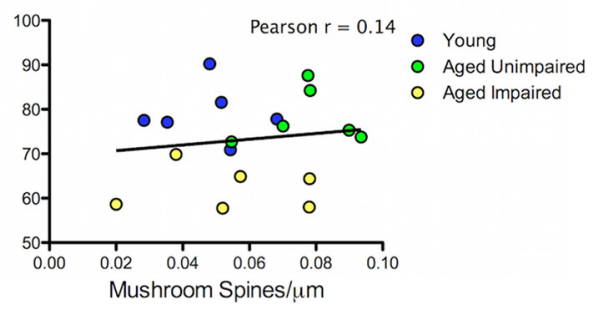

Figure 3. Thin spine density correlates with DR cognitive performance. $A$, Total spine density was significantly correlated with behavioral performance on the DR task such that impaired monkeys had the lowest spine density. $\boldsymbol{B}$, When thin spines were analyzed separately, a significant correlation was seen between thin spine density and DR performance. $\boldsymbol{C}$, When mushroom spines were analyzed separately, no correlation was seen between mushroom spine density and DR performance. ${ }^{*} p<0.05$.

\section{Correlation between DR performance and spine density in area $7 \mathrm{a}$}

DR performance positively correlates with total spine density, with better DR performance predicted by higher spine densities (Pearson $r=0.54, p=0.02, N=18$ ) (Fig. 3A). Thin spine density alone also correlates with DR performance (Pearson $r=0.50, p=$ $0.03, N=18$; Fig. $3 B$ ), but no significant correlation was observed between mushroom spine density and DR performance (Pearson $r=0.14, p=0.58, N=18$; Fig. $3 C$ ). Thus, the relationship between working memory and synaptic density is driven only by thin spines.

Importantly, the positive correlation between total spine density and DR performance is also found when examining the aged group alone (Pearson $r=0.62, p=0.03, N=12$ ). Interestingly, this correlation is driven by a combination of thin and mushroom spines but does not reach significance when either spine type is examined individually (aged thin spine: Pearson $r=0.52$, $p=0.08$; aged mushroom spine: Pearson $r=0.48, p=0.12, N=$ 12). In contrast, the behavioral performance of the young monkeys alone does not correlate with spine density (young total spine: Pearson $r=-0.54, p=0.27$; young thin spine: Pearson $r=-0.51, p=0.30$; young mushroom spine: Pearson $r=-0.03$, $p=0.9, N=6$ ). Thus, the overall correlation between spine density and DR performance appears to reflect both a common effect of age on both measures, but also a relationship between DR performance and spine density only in the aged monkeys in which greater spine density is associated with better behavioral performance.

The above observation is supported by linear mixed models analyses, which revealed both age group and the interaction of age and DR performance to be significant predictors of total spine density $\left(\right.$ age: $F_{(1, \sim 13.34)}=22.98, p=3.27 \times 10^{-4}$; age $\times \mathrm{DR}$ : $F_{(1, \sim 13.81)}=6.70, p=0.02$, linear mixed model). Similarly, both age group and the interaction of age and DR performance were significant predictors of thin spine density, as well as dendritic tree (apical or basal) origin (age: $F_{(1, \sim 13.66)}=25.35, p=1.97 \times$ $10^{-4}$; age $\times$ DR: $F_{(1, \sim 14.13)}=4.72, p=0.047$; tree origin: $F_{(1, \sim 616.43)}=3.98, p=0.047$, linear mixed model). However, neither age group nor the interaction of age and DR performance was a significant predictor of mushroom spine density (age: $F_{(1, \sim 14.10)}=2.42, p=0.14$; age $\times \mathrm{DR}: F_{(1, \sim 14.26)}=0.44, p=0.52$, linear mixed model). Thus, in addition to effects of age on both DR and spine density, total and thin spine density also uniquely predict behavioral performance in the DR task.

Correlation between DNMS performance and spine density in area $7 \mathbf{a}$

To examine the specificity of the relationship between spine density and spatial working memory performance in aged monkeys, we also examined performance on DNMS, a test of visual recognition memory. A significant correlation was observed between total spine density and DNMS performance (Pearson $r=0.68$, $\left.p=1.8 \times 10^{-3}, N=18\right)$. Similarly, a significant correlation was observed between thin spine density and DNMS performance (Pearson $r=0.70, p=1.1 \times 10^{-3}, N=18$ ). No significant correlation was observed between mushroom spine density and DNMS performance (Pearson $r=-0.32, p=0.20, N=18$ ). However, when we examined either the aged or young monkeys alone, no significant correlations were observed between spine density (total, thin, or mushroom) and DNMS performance (aged total spine: Pearson $r=0.26, p=0.42$; aged thin spine: Pearson $r=0.28, p=0.37$; aged mushroom spine: Pearson $r=$ $-0.32, p=0.20, N=12$; young total spine: Pearson $r=0.23, p=$ 0.66 ; young thin spine: Pearson $r=0.03, p=0.96$; young mushroom spine: Pearson $r=-0.14, p=0.80, N=6)$. Thus, the overall correlation between spine density and DNMS performance appears to reflect a main effect of age on both measures: within each group, the relationship between DNMS performance and spine density is flat, but older monkeys tend to have both lower spine density and worse DNMS performance.

Based on this finding, we expected that DNMS performance would not be a significant predictor of spine density in LMM analyses. Indeed, neither DNMS performance nor the interaction of age with DNMS performance was a significant predictor of total spine density (DNMS: $F_{(1, \sim 12.74)}=0.61, p=0.14$; age $\times$ DNMS: $F_{(1, \sim 12.74)}=0.05, p=0.82$, linear mixed model). DNMS performance and the interaction of age with DNMS performance were also not predictors of either thin or mushroom spine density (thin spine DNMS: $F_{(1, \sim 12.60)}=0.17, p=0.69$; age $\times$ DNMS: $F_{(1, \sim 12.60)}=0.42, p=0.52$; mushroom spine DNMS: $F_{(1, \sim 13.54)}=0.06$, $p=0.82$; age $\times$ DNMS: $F_{(1, \sim 13.54)}=1.1 \times 10^{-3}, p=0.97$, linear mixed model). In these models, age alone predicted thin spine density $\left(F_{(1, \sim 11.91)}=5.36, p=0.039\right)$, but not total spine density $\left(F_{(1, \sim 12.15)}=2.47, p=0.14\right)$ or mushroom spine density $\left(F_{(1, \sim 13.21)}=1.10, p=0.31\right)$. These results are consistent with our correlation analyses, in which there was no relationship between spine density and DNMS performance for either the aged or the young animals when analyzed separately. A correlation between spine density and performance is seen when both are analyzed together because of a common main effect of aging on both spine density and DNMS performance. Thus, aging causes both decreased spine density and impaired DNMS performance, but area 7a spine density does not uniquely predict DNMS performance for either the young or the aged animals. This is in contrast to the DR results, where spine density significantly correlates with DR performance for the aged animals $(p=0.03)$, and with the LMM analyses of DR behavior where the interaction of age with DR performance was a significant predictor of spine 


\section{Spine Head Volume}

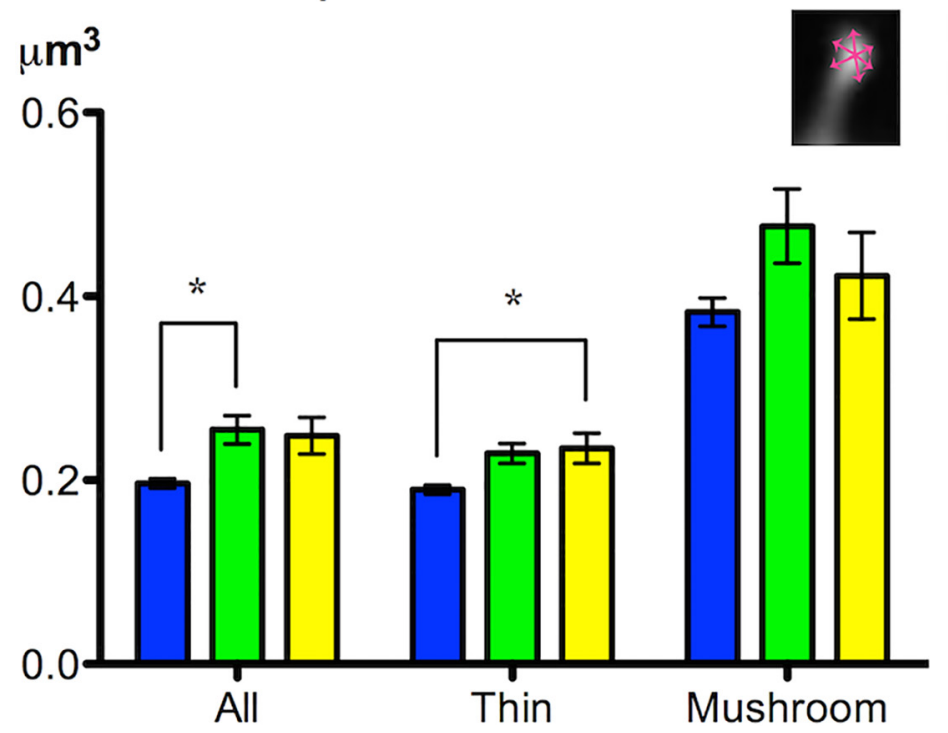

Figure 4. Age-related increase in dendritic spine volume in area 7a. Thin spine head volume was increased for Al. Total spine head volume was increased for AU monkeys, but a specific increase in thin spine head volume was seen in Al monkeys. ${ }^{*} p<0.05$.

density. This supports the notion that these tasks test different aspects of cognitive ability, and that the DR behavioral deficit seen in the AI monkeys is not due to a global cognitive impairment.

\section{Correlation between OD performance and spine density in area $7 \mathbf{a}$}

We also considered whether any visual processing or motivational deficits, reflected in individual differences in OD task performance, might be related to morphological measures in area $7 \mathrm{a}$. No significant correlations were observed between total spine density, thin spine density, or mushroom spine density, and OD performance (total spine: Pearson $r=0.31, p=0.23$; thin spine: Pearson $r=0.34, p=0.16$; mushroom spine: Pearson $r=-0.33$, $p=0.18, N=18$ ). In our linear mixed model analyses, neither OD performance nor the interaction of age with OD performance significantly predicted total, thin, or mushroom spine density $(F<0.56, p>0.47$, linear mixed model $)$. Thus, the relationships between spine density and DR task performance in aged monkeys are specific to spatial working memory and do not reflect general memory deficits with aging (reflected by DNMS performance) or overall visual ability and motivation (reflected by OD performance).

\section{Effects of aging on dendritic spine morphology in area 7a}

We next examined morphological measures of individual spines to assess age-related changes in spine size. Both AU and AI monkeys had larger spine head volumes compared with young monkeys, although this size difference did not reach statistical significance in AI monkeys $\left(F_{(2,15)}=4.62, p=0.03\right.$, one-way ANOVA; AU vs young: $p=0.04$; AI vs young: $p=0.06$; AI vs AU: $p=0.95$, Bonferroni multiple comparison tests; Fig. 4; Table 1). This overall greater spine head size is primarily due to age-related increase in thin spine head volume. Although the magnitude of difference of groups AI and AU relative to young was similar, only AI reached significance $\left(F_{(2,15)}=4.49, p=0.03\right.$, one-way ANOVA; AI vs young: $p=0.04$; AU vs young: $p=0.07$; AI vs AU: $p=0.94$; Fig. 4; Table 1) When mushroom spines were analyzed alone, no significant difference in mushroom spine average head volume was seen between any groups $\left(F_{(2,15)}=1.61, p=0.23\right.$, one-way ANOVA; AU vs young: $p=0.21$; AI vs young: $p=0.73$; AI vs AU: $p=0.57$, Bonferroni multiple comparison tests; Fig. 4; Table 1).

To probe more subtle differences in age-related spine head volume changes, we also examined the distribution of spine sizes within each group. The cumulative distribution frequency of spine head volumes was plotted, and differences between groups were investigated using the two-sample Kolmogorov-Smirnov test, a nonparametric test comparing distributions of continuous variables. Compared with young monkeys, both AU and AI monkeys had a significant rightward shift (toward larger sizes) in spine head volume distribution $\left(p=6.7 \times 10^{-43}\right.$ and $p=2.0 \times$ $10^{-55}$, respectively, Kolmogorov-Smirnov test, Bonferronicorrected $\alpha=0.02$; Fig. 5A). AU and AI monkeys did not differ significantly ( $p=0.06$, Kolmogorov-Smirnov test, Bonferronicorrected $\alpha=0.02$; Fig. 5A). Thin spines also showed a significant rightward shift for both $\mathrm{AU}$ and $\mathrm{AI}$ monkeys compared with young $\left(p=6.9 \times 10^{-24}\right.$ and $p=2.4 \times 10^{-43}$, respectively, Kolmogorov-Smirnov test, Bonferroni-corrected $\alpha=0.02$; Fig. $5 B)$. Importantly, here we also observed a significant rightward shift of AI compared with AU $\left(p=2.0 \times 10^{-4}\right.$, KolmogorovSmirnov test, Bonferroni-corrected $\alpha=0.02$; Fig. $5 B$ ). Therefore, even though mean spine head volumes do not differ between AU and AI (Fig. 4), there are indeed subtle changes in the distribution of thin spines associated with age-related cognitive impairment. The overall lower prevalence of the smallest of thin spines in the AI group (Fig. $5 B$ ) suggests that the smallest thin spines are the most vulnerable to aging and the most relevant to working memory. Age-related changes in the distribution of mushroom spine head volumes mirrored those seen in total spine head volume distribution, with a rightward shift observed in both AU and AI compared with young $\left(p=2.9 \times 10^{-13}\right.$ and $p=1.6 \times 10^{-7}$, respectively, Kolmogorov-Smirnov test, Bonferroni-corrected $\alpha=0.02$; Fig. $5 C$ ), but no differences between $\mathrm{AU}$ and $\mathrm{AI}$ ( $p=$ 0.13 , Kolmogorov-Smirnov test, Bonferroni-corrected $\alpha=$ $0.02)$. 

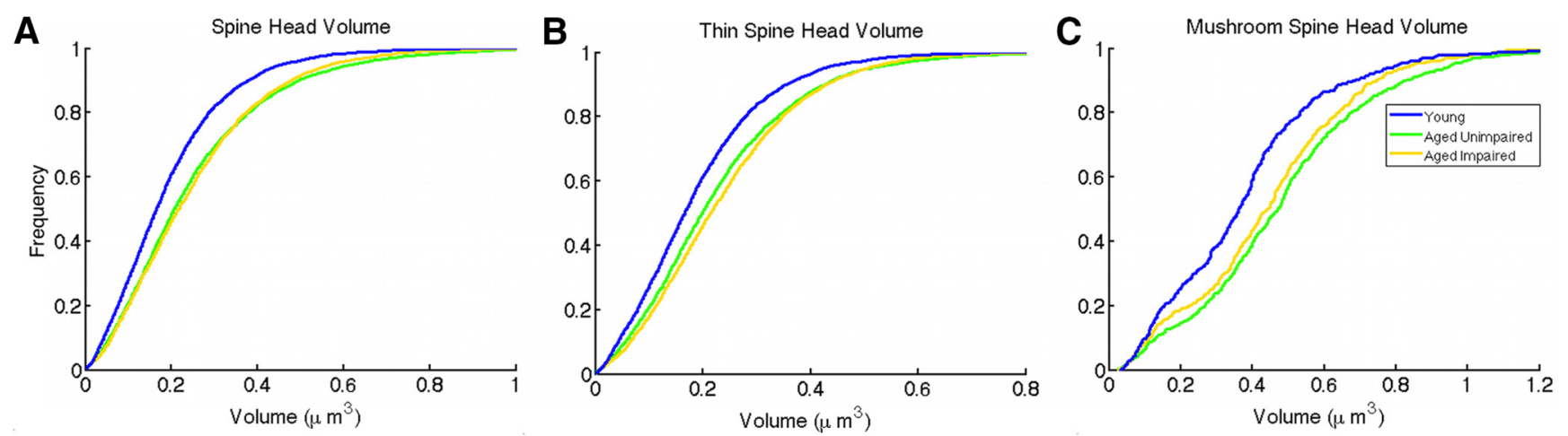

Figure 5. Al monkeys have significantly larger thin spines than AU monkeys. A, Total spine head volume was significantly increased for both AU monkeys and Al monkeys relative to young monkeys. $\boldsymbol{B}$, Mushroom spine head volume was significantly increased for both AU monkeys and Al monkeys relative to young monkeys. $\boldsymbol{C}$, Thin spine head volume was significantly increased for both AU monkeys and AI monkeys relative to young monkeys. Thin spine head volume was also significantly increased for Al monkeys compared with AU monkeys for thin spines $<0.5 \mu \mathrm{m}^{3}$.

A

B

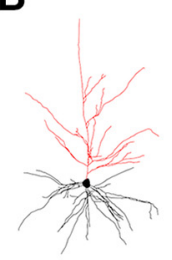

C

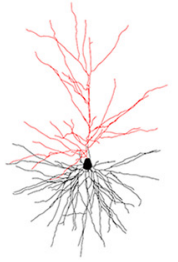

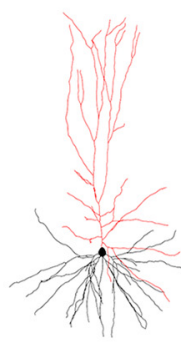
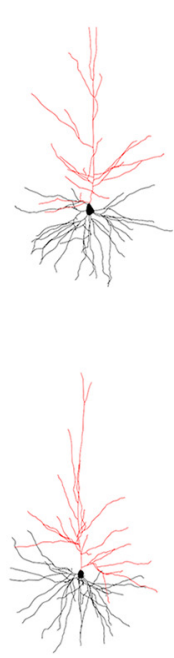

D
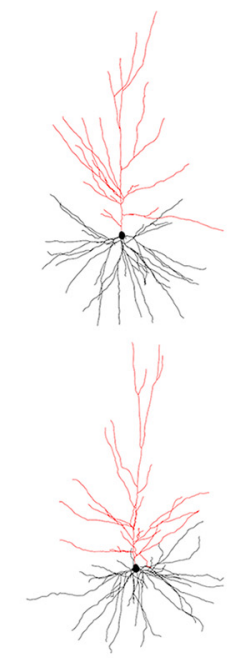

E

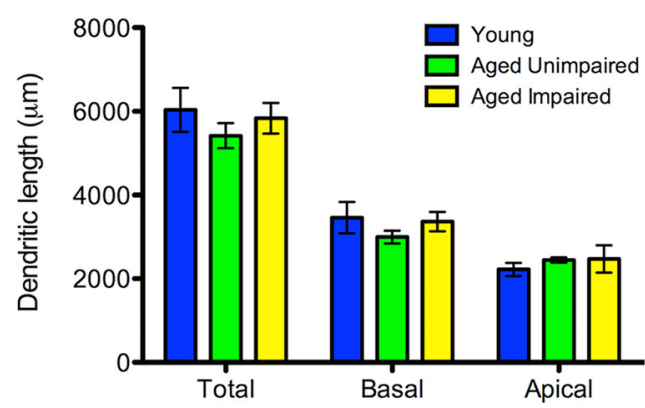

Dendritic Branching

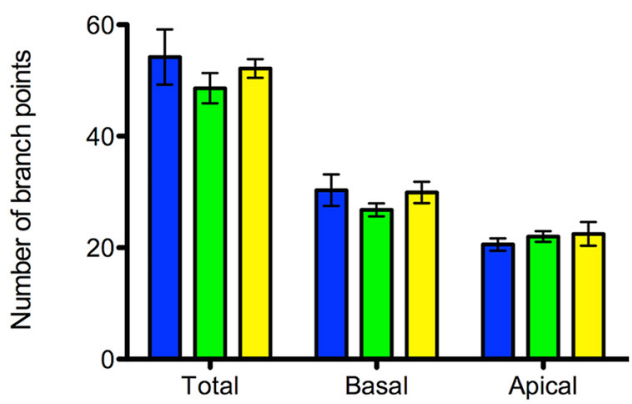

Figure 6. Area 7a dendritic length and branching are not affected by aging. $\boldsymbol{A}-\boldsymbol{C}$, Representative tracings from young $(\boldsymbol{A}), \mathrm{AU}(\boldsymbol{B})$, and Al $(\boldsymbol{C})$ animals. Black represents basal dendrites. Red represents apical dendrites. $\boldsymbol{D}$, No age-related changes were seen in total dendritic length or when either basal or apical dendritic length was analyzed separately. $\boldsymbol{E}$, No age-related changes were seen in total dendritic branching or when either basal or apical dendritic branching was analyzed separately.

No significant correlation was observed between head volume (total, thin, or mushroom) and DR behavioral performance $\left(R^{2}\right.$ values $<0.04$, $p$ values $>0.41, N=18$, data not shown).

\section{Effects of aging on dendritic length and branching}

We next examined age-related changes to dendritic morphology in area $7 \mathrm{a}$, first assessing overall dendritic length. No significant difference in total dendritic length was seen between any groups $\left(F_{(2,6)}=0.59, p=0.58\right.$, one-way ANOVA; AI vs young: $p=0.57$ : AU vs young: $p=0.94$ : AI vs AU: $p=0.76$, Bonferroni multiple comparison tests; Fig. 6A; Table 1). There was also no difference when either basal or apical trees were analyzed separately.
Next, we examined potential changes to the number of dendritic branch points. Again, no significant difference was observed in the number of total branch points between any groups $\left(F_{(2,6)}=0.70, p=0.53\right.$, one-way ANOVA; AI vs young: $p=0.51$ : AU vs young: $p=0.90$; AI vs AU: $p=0.75$; Fig. $6 B$; Table 1 ), and no differences were observed when basal and apical trees were analyzed separately.

Effects of aging on the complexity of dendritic arborization Last, we used Sholl analyses to determine whether there are agerelated changes to the complexity of the dendritic arbor. No significant difference was seen in the number of whole neuron 

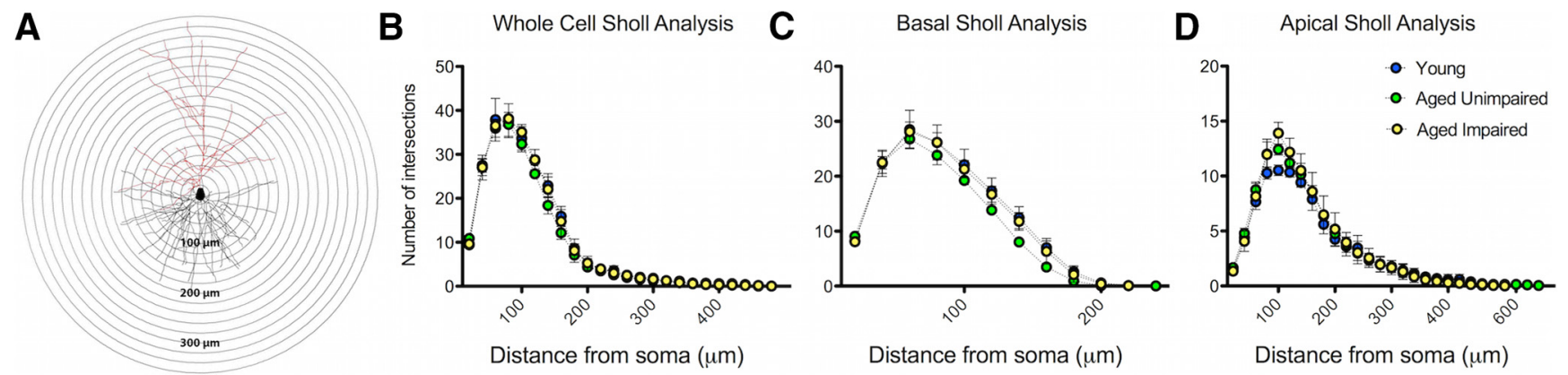

Figure 7. Area 7a dendritic arborization is not affected by aging. $A$, Representative tracing showing Sholl crossings every $20 \mu \mathrm{m}$. Black represents basal dendrites. Red represents apical dendrites. $B$, Sholl analysis revealed no age-related changes in the complexity of dendritic arborization as measured by the number of intersections at specified distances away from the soma. $C$, When basal branches were analyzed separately, no age-related changes were seen in the complexity of basal branch arborization. $\boldsymbol{D}$, When apical branches were analyzed separately, no age-related changes were seen in the complexity of apical branch arborization.

dendritic tree crossings between any groups $\left(F_{(2,22)}=0.48, p=\right.$ 0.64 , repeated-measures ANOVA; AU vs young: $p=0.39$; AI vs young: $p=0.89$; AI vs AU: $p=0.48$, Bonferroni multiple comparison tests; Fig. $7 A$; Table 1). There was also no difference when either basal or apical branches were analyzed alone (basal $F_{(2,22)}=0.73$, $p=0.52$, repeated-measures ANOVA; AU vs young: $p=0.34$; AI vs young: $p=0.86$; AI vs $\mathrm{AU}: p=0.27$, Bonferroni multiple comparison tests; Fig. $7 B$; apical $F_{(2,22)}=0.34, p=0.72$, repeated-measures ANOVA; AU vs young: $p=0.30$ : AI vs young: $p=0.57$; AI vs AU: $p=0.96$, Bonferroni multiple comparison tests; Figure 7C; Table 1). We used a linear mixed model to look for significant predictors of number of crossings, using age group (young vs aged) and distance as fixed factors, and monkey as a random factor, and found results consistent with the repeatedmeasures ANOVA above. Dendritic tree Sholl crossings were not significantly predicted by age group $\left(F_{(1, \sim 7.0)}=0.75, p=0.42\right.$, linear mixed model), indicating that dendritic complexity is not significantly different between young and aged monkeys.

\section{Discussion}

\section{Cognitive aging and synaptic health}

We present evidence supporting our hypothesis that cognitive aging is driven primarily by synaptic changes rather than structural alterations, such as dendritic atrophy or neuronal loss (Morrison and Baxter, 2012, 2014). Dendritic spines are the major site of excitatory synapses onto cortical neurons. Aged monkeys have significantly fewer spines in area 7a, with AI monkeys showing the greatest loss (Fig. 2). This loss of excitatory synapses correlates with decreased working memory performance (Fig. 3). In contrast, no age-related changes in dendritic length or arborization occur (Figs. 6, 7). These results are consistent with previous findings in the primate dlPFC, where synapse loss correlates with age-related cognitive impairment (Peters et al., 2008; Dumitriu et al., 2010) despite no age-related changes in dendritic length or arborization in either the superior temporal sulcus (Duan et al., 2003) or in locally projecting neurons in area 46 (Kabaso et al., 2009). In vivo two-photon work in the mouse shows learning is associated with sprouting of new spines (Holtmaat et al., 2006; Yang et al., 2009) and enhanced spine turnover positively correlates with learning and memory (Frank et al., 2018). Relevantly, spine turnover is decreased with aging (Grutzendler et al., 2002; Holtmaat et al., 2005). It is possible that our observed age-related spine loss reflects age-related decreases in spine turnover.

\section{Thin spines and aging}

Importantly, we show that age-related decrease in spine density in area 7a is specific to thin spines (Fig. 2). Decreased spine turnover would require that new inputs potentiate already existing spines, possibly leading to increased spine head size (Yang et al., 2008). Consistently, our observed loss of thin spines is accompanied by an increase in thin spine head volume (Fig. 4), with AI monkeys having larger thin spines than AU monkeys (Fig. 5B). This shift toward larger head volumes is specific to the smallest thin spines (Fig. 5B), suggesting that the smallest thin spines are most vulnerable to aging. We report a slight, but significant, agerelated increase in mushroom spine density in AU monkeys (Fig. 2). This could reflect a compensatory mechanism, explaining why AU monkeys maintain working memory performance despite thin spine loss in both aged groups.

Our thin spine results are consistent with work in primate area 46, where aged monkeys have a shift toward larger thin spine head volumes primarily for the smallest thin spines (Dumitriu et al., 2010; Young et al., 2014). However, age-related changes in spine size are not uniform across cortical regions, as no age-related size changes are seen in primate V1 thin spines (Young et al., 2014). In aged rodent $\mathrm{mPFC}$, a specific loss of the smallest thin spines and reduced spine morphological remodeling in response to stress are seen, suggestive of age-related decreased plasticity (Bloss et al., 2011). Additionally, aged rodents have a 50\% increase in synaptic phosphorylated LIM kinase (pLIMK) specifically at large spines (Bloss et al., 2013). pLIMK stabilizes actin (Arber et al., 1998; Yang et al., 1998), and these results suggest that age-related increases in synaptic pLIMK drive age-related increases in spine size (Bloss et al., 2013). It is possible this same mechanism contributes to the age-related increase in thin spine volume seen in primate area $7 \mathrm{a}$.

\section{Thin spines and working memory}

Interestingly, despite no differences in DR performance between $\mathrm{Y}$ and $\mathrm{AU}$, both aged groups have significantly fewer thin spines than young. Potentially, young monkeys have a thin spine reserve, and behavioral deficits emerge once spine loss crosses a certain threshold (Hao et al., 2007). This hypothesis is supported by the correlation between thin spine density and DR performance within the aged monkeys. Computational models predict that thin spine dynamics support working memory by conferring plasticity necessary for rapid, context-dependent updating of neural networks (Kasai et al., 2003; Arnsten et al., 2012). Both area 7a (Quintana and Fuster, 1992; Constantinidis and Stein- 
metz, 1996) and area 46 (Fuster and Alexander, 1971; Kubota and Niki, 1971) have delay cells, a subset of neurons persistently active during the DR delay period (Fuster and Alexander, 1971; Kubota and Niki, 1971). Although there is debate about the exact information encoded by delay cell persistent firing (Funahashi et al., 1989; Goldman-Rakic, 1995; Rowe et al., 2000; Tsujimoto and Postle, 2012; Konecky et al., 2017), significantly decreased delay cell firing occurs on DR error trials compared with correct trials (Funahashi et al., 1989; Zhou et al., 2013). Analyses in aged monkeys support a relationship between mechanisms contributing to delay cell firing and age-related working memory impairments (Wang et al., 2011). Our results hint at a possible functional relationship between thin spine density, delay cell firing, and working memory performance. We postulate that area 7a in aged monkeys would show an age-related decrease in delay cell firing similar to area 46 (Wang et al., 2011). Although aged monkeys also show impaired DNMS performance, the relationship with area $7 \mathrm{a}$ spine density is different, with correlations being driven by common effects of age on both measures rather than a distinct coupling between spine density and behavioral performance.

\section{Area $7 \mathrm{a}$ and working memory}

We note that thin spine density in both areas $7 \mathrm{a}$ and 46 correlates with cognitive performance on dlPFC-dependent tasks (Dumitriu et al., 2010). Aging causes decreased thin spine density and increased thin spine head size in both regions (Dumitriu et al., 2010). Similarities between these two regions extend beyond the synapse. Areas $7 \mathrm{a}$ and 46 are reciprocally connected (Cavada and Goldman-Rakic, 1989a,b) and coactive during working memory tasks (Friedman and Goldman-Rakic, 1994). Notably, both regions exhibit delay cell firing (Fuster and Alexander, 1971; Kubota and Niki, 1971; Quintana and Fuster, 1992; Constantinidis and Steinmetz, 1996). Although lesions of area 46 cause profound working memory impairments (Funahashi et al., 1990), the role of area $7 \mathrm{a}$ is not as clear. Bilateral ablation of the combined areas $7 \mathrm{a}, 7 \mathrm{~b}$, and 7ip causes an initial impairment in DR performance that recovers after a few days (Pu et al., 1993). Cooling area 7 results in slow and inaccurate eye movements and longer reaction times but does not change overall DR performance (Quintana et al., 1989). However, when the cue and response stimuli are farther apart in space, such that the monkey cannot create a composite mental image of the stimuli, cooling area 7 a results in working memory impairments as severe as prefrontal cooling (Quintana and Fuster, 1993). Visual evoked potentials recorded over the principal sulcus are decreased in monkeys with IPS lesions, suggesting a functional information flow from the IPS to the dlPFC during working memory (Pu et al., 1993). Studies looking at the relationship between area 7ip (adjacent to area 7a) and area $8 \mathrm{a}$ (adjacent to area 46) show similar results: areas 7ip and $8 \mathrm{a}$ are coactive during a working memory task (Chafee and Goldman-Rakic, 1998), and cooling either area significantly alters the neuronal activity in the other region (Chafee and Goldman-Rakic, 2000). In humans, patients with right parietal damage show working memory impairments (Pisella et al., 2004; Berryhill and Olson, 2008; Koenigs et al., 2009). Our result showing a correlation between area $7 \mathrm{a}$ thin spine density and DR behavioral performance supports the idea of information flow from the IPS to the dIPFC, thereby connecting area $7 \mathrm{a}$ with working memory performance.

\section{Area 7a morphology}

This study is the first to report primate area 7a spine density and dendritic morphology in young adult and aged monkeys. One study looked at this region in juvenile monkeys 14-20 months of age (Elston and Rosa, 1997). They reported area 7a basal spine density as $0.98 \pm 0.25$ spines $/ \mu \mathrm{m}$, slightly higher than what we report for young adult monkeys. This difference is possibly due to synaptic pruning, which occurs as the juvenile monkey matures (Rakic et al., 1986).

In the context of our prior work (Dumitriu et al., 2010; Young et al., 2014), we note some interesting similarities and differences between area 7a, area 46, and V1. Although all three regions are predominated by thin spines, age-related spine loss is only seen in areas $7 \mathrm{a}$ and 46 . Only thin spine density in areas 7a or 46 correlates with behavioral performance. However, area 46 has almost double the spine density of area $7 \mathrm{a}$ or V1. Of these three cortical regions, area 46 has the highest convergence of corticocortical inputs and V1 has the lowest, suggesting that this integrative function relies on highly plastic axospinous synapses. Current analyses do not permit us to determine whether there are subclasses of thin spines with varying degrees of vulnerability. Future work will investigate the potential heterogeneity in the molecular phenotype of spine classes that might be linked to differential synaptic vulnerability and resilience.

In conclusion, the present results confirm our prior observation that cognitive aging is driven by synaptic alterations rather than changes to dendritic morphology. This work adds weight to the theory that thin spines contribute to working memory performance, and strengthens the link between area $7 \mathrm{a}$ and working memory. Our data show that the correlation between age-related working memory decline and thin spine loss is not limited to the dlPFC but includes an association region heavily interconnected with dlPFC.

\section{References}

Arber S, Barbayannis FA, Hanser H, Schneider C, Stanyon CA, Bernard O, Caroni P (1998) Regulation of actin dynamics through phosphorylation of cofilin by LIM-kinase. Nature 393:805-809. CrossRef Medline

Arnsten AF, Wang MJ, Paspalas CD (2012) Neuromodulation of thought: flexibilities and vulnerabilities in prefrontal cortical network synapses. Neuron 76:223-239. CrossRef Medline

Bachevalier J, Landis LS, Walker LC, Brickson M, Mishkin M, Price DL, Cork LC (1991) Aged monkeys exhibit behavioral deficits indicative of widespread cerebral dysfunction. Neurobiol Aging 12:99-111. CrossRef Medline

Bartus RT, Fleming D, Johnson HR (1978) Aging in the rhesus monkey: debilitating effects on short-term memory. J Gerontol 33:858-871. CrossRef Medline

Bates D, Maechler M, Bolker B, Walker S (2015) Fitting Linear Mixed-Effects Models Using lme4. Journal of Statistical Software 67:1-48. CrossRef

Berryhill ME, Olson IR (2008) The right parietal lobe is critical for visual working memory. Neuropsychologia 46:1767-1774. CrossRef Medline

Bloss EB, Janssen WG, Ohm DT, Yuk FJ, Wadsworth S, Saardi KM, McEwen BS, Morrison JH (2011) Evidence for reduced experience-dependent dendritic spine plasticity in the aging prefrontal cortex. J Neurosci 31: 7831-7839. CrossRef Medline

Bloss EB, Puri R, Yuk F, Punsoni M, Hara Y, Janssen WG, McEwen BS, Morrison JH (2013) Morphological and molecular changes in aging rat prelimbic prefrontal cortical synapses. Neurobiol Aging 34:200-210. CrossRef Medline

Cavada C, Goldman-Rakic PS (1989a) Posterior parietal cortex in rhesus monkey: I. Parcellation of areas based on distinctive limbic and sensory corticocortical connections. J Comp Neurol 287:393-421. CrossRef Medline

Cavada C, Goldman-Rakic PS (1989b) Posterior parietal cortex in rhesus monkey: II. Evidence for segregated corticocortical networks linking sensory and limbic areas with the frontal lobe. J Comp Neurol 287:422-445. CrossRef Medline

Chafee MV, Goldman-Rakic PS (1998) Matching patterns of activity in primate prefrontal area $8 \mathrm{a}$ and parietal area 7ip neurons during a spatial working memory task. J Neurophysiol 79:2919-2940. CrossRef Medline 
Chafee MV, Goldman-Rakic PS (2000) Inactivation of parietal and prefrontal cortex reveals interdependence of neural activity during memoryguided saccades. J Neurophysiol 83:1550-1566. CrossRef Medline

Constantinidis C, Steinmetz MA (1996) Neuronal activity in posterior parietal area 7a during the delay periods of a spatial memory task. J Neurophysiol 76:1352-1355. CrossRef Medline

Duan H, Wearne SL, Rocher AB, Macedo A, Morrison JH, Hof PR (2003) Age-related dendritic and spine changes in corticocortically projecting neurons in macaque monkeys. Cereb Cortex 13:950-961. CrossRef Medline

Dumitriu D, Hao J, Hara Y, Kaufmann J, Janssen WG, Lou W, Rapp PR, Morrison JH (2010) Selective changes in thin spine density and morphology in monkey prefrontal cortex correlate with aging-related cognitive impairment. J Neurosci 30:7507-7515. CrossRef Medline

Dumitriu D, Rodriguez A, Morrison JH (2011) High-throughput, detailed, cell-specific neuroanatomy of dendritic spines using microinjection and confocal microscopy. Nat Protoc 6:1391-1411. CrossRef Medline

Elston GN, Rosa MG (1997) The occipitoparietal pathway of the macaque monkey: comparison of pyramidal cell morphology in layer III of functionally related cortical visual areas. Cereb Cortex 7:432-452. CrossRef Medline

Frank AC, Huang S, Zhou M, Gdalyahu A, Kastellakis G, Silva TK, Lu E, Wen X, Poirazi P, Trachtenberg JT, Silva AJ (2018) Hotspots of dendritic spine turnover facilitate clustered spine addition and learning and memory. Nat Commun 9:422. CrossRef Medline

Friedman HR, Goldman-Rakic PS (1994) Coactivation of prefrontal cortex and inferior parietal cortex in working memory tasks revealed by $2 \mathrm{DG}$ functional mapping in the rhesus monkey. J Neurosci 14:2775-2788. CrossRef Medline

Funahashi S, Bruce CJ, Goldman-Rakic PS (1989) Mnemonic coding of visual space in the monkey's dorsolateral prefrontal cortex. J Neurophysiol 61:331-349. CrossRef Medline

Funahashi S, Bruce CJ, Goldman-Rakic PS (1990) Visuospatial coding in primate prefrontal neurons revealed by oculomotor paradigms. J Neurophysiol 63:814-831. CrossRef Medline

Fuster JM, Alexander GE (1971) Neuron activity related to short-term memory. Science 173:652-654. CrossRef Medline

Goldman-Rakic PS (1990) Cellular and circuit basis of working memory in prefrontal cortex of nonhuman primates. Prog Brain Res 85:325-335; discussion 335-336. Medline

Goldman-Rakic PS (1995) Cellular basis of working memory. Neuron 14: 477-485. CrossRef Medline

Grutzendler J, Kasthuri N, Gan WB (2002) Long-term dendritic spine stability in the adult cortex. Nature 420:812-816. CrossRef Medline

Hao J, Rapp PR, Leffler AE, Leffler SR, Janssen WG, Lou W, McKay H, Roberts JA, Wearne SL, Hof PR, Morrison JH (2006) Estrogen alters spine number and morphology in prefrontal cortex of aged female rhesus monkeys. J Neurosci 26:2571-2578. CrossRef Medline

Hao J, Rapp PR, Janssen WG, Lou W, Lasley BL, Hof PR, Morrison JH (2007) Interactive effects of age and estrogen on cognition and pyramidal neurons in monkey prefrontal cortex. Proc Natl Acad Sci U S A 104:1146511470. CrossRef Medline

Hara Y, Yuk F, Puri R, Janssen WG, Rapp PR, Morrison JH (2014) Presynaptic mitochondrial morphology in monkey prefrontal cortex correlates with working memory and is improved with estrogen treatment. Proc Natl Acad Sci U S A 111:486-491. CrossRef Medline

Hara Y, Yuk F, Puri R, Janssen WG, Rapp PR, Morrison JH (2016) Estrogen restores multisynaptic boutons in the dorsolateral prefrontal cortex while promoting working memory in aged rhesus monkeys. J Neurosci 36:901910. CrossRef Medline

Hartig F (2018) DHARMa: residual diagnostics for hierarchical (multi-lev$\mathrm{el} /$ mixed) regression models. $\mathrm{R}$ package version 0.2.0. https://CRAN.Rproject.org/package $=$ DHARMa.

Holtmaat AJ, Trachtenberg JT, Wilbrecht L, Shepherd GM, Zhang X, Knott GW, Svoboda K (2005) Transient and persistent dendritic spines in the neocortex in vivo. Neuron 45:279-291. CrossRef Medline

Holtmaat A, Wilbrecht L, Knott GW, Welker E, Svoboda K (2006) Experience-dependent and cell-type-specific spine growth in the neocortex. Nature 441:979-983. CrossRef Medline

Kabaso D, Coskren PJ, Henry BI, Hof PR, Wearne SL (2009) The electrotonic structure of pyramidal neurons contributing to prefrontal cortical circuits in macaque monkeys is significantly altered in aging. Cereb Cortex 19:2248-2268. CrossRef Medline

Kasai H, Matsuzaki M, Noguchi J, Yasumatsu N, Nakahara H (2003) Structure-stability-function relationships of dendritic spines. Trends Neurosci 26:360-368. CrossRef Medline

Koenigs M, Barbey AK, Postle BR, Grafman J (2009) Superior parietal cortex is critical for the manipulation of information in working memory. J Neurosci 29:14980-14986. CrossRef Medline

Konecky RO, Smith MA, Olson CR (2017) Monkey prefrontal neurons during Sternberg Task Performance: full contents of working memory or most recent item? J Neurophysiol 117:2269-2281. CrossRef Medline

Kubota K, Niki H (1971) Prefrontal cortical unit activity and delayed alternation performance in monkeys. J Neurophysiol 34:337-347. CrossRef Medline

Kuznetsova A, Brockhoff PB, Christensen RHB (2017) lmerTest Package: Tests in Linear Mixed Effects Models. Journal of Statistical Software 82: 1-26. CrossRef

Luebke J, Barbas H, Peters A (2010) Effects of normal aging on prefrontal area 46 in the rhesus monkey. Brain Res Rev 62:212-232. CrossRef Medline

Morrison JH, Baxter MG (2012) The ageing cortical synapse: hallmarks and implications for cognitive decline. Nat Rev Neurosci 13:240-250. CrossRef Medline

Morrison JH, Baxter MG (2014) Synaptic health. JAMA Psychiatry 71:835837. CrossRef Medline

Ohm DT, Bloss EB, Janssen WG, Dietz KC, Wadsworth S, Lou W, Gee NA, Lasley BL, Rapp PR, Morrison JH (2012) Clinically relevant hormone treatments fail to induce spinogenesis in prefrontal cortex of aged female rhesus monkeys. J Neurosci 32:11700-11705. CrossRef Medline

Peters A, Leahu D, Moss MB, McNally KJ (1994) The effects of aging on area 46 of the frontal cortex of the rhesus monkey. Cereb Cortex 4:621-635. CrossRef Medline

Peters A, Sethares C, Luebke JI (2008) Synapses are lost during aging in the primate prefrontal cortex. Neuroscience 152:970-981. CrossRef Medline

Pisella L, Berberovic N, Mattingley JB (2004) Impaired working memory for location but not for colour or shape in visual neglect: a comparison of parietal and non-parietal lesions. Cortex 40:379-390. CrossRef Medline

Pu X, Ma Y, Cai J (1993) A study on the effect of lesions of area 7 of the parietal cortex on the short-term visual spatial memory of rhesus monkeys (Macaca mulatta). Brain Res 600:187-192. CrossRef Medline

Qi XL, Katsuki F, Meyer T, Rawley JB, Zhou X, Douglas KL, Constantinidis C (2010) Comparison of neural activity related to working memory in primate dorsolateral prefrontal and posterior parietal cortex. Front Syst Neurosci 4:12. CrossRef Medline

Quintana J, Fuster JM (1992) Mnemonic and predictive functions of cortical neurons in a memory task. Neuroreport 3:721-724. CrossRef Medline

Quintana J, Fuster JM (1993) Spatial and temporal factors in the role of prefrontal and parietal cortex in visuomotor integration. Cereb Cortex 3:122-132. CrossRef Medline

Quintana J, Fuster JM, Yajeya J (1989) Effects of cooling parietal cortex on prefrontal units in delay tasks. Brain Res 503:100-110. CrossRef Medline

R Core Team (2018) R: a language and environment for statistical computing. R Foundation for Statistical Computing, Vienna. https://www.Rproject.org/.

Rakic P, Bourgeois JP, Eckenhoff MF, Zecevic N, Goldman-Rakic PS (1986) Concurrent overproduction of synapses in diverse regions of the primate cerebral cortex. Science 232:232-235. CrossRef Medline

Rapp PR (1990) Visual discrimination and reversal learning in the aged monkey (Macaca mulatta). Behav Neurosci 104:876-884. CrossRef Medline

Rapp P (1993) Neuropsychological analysis of learning and memory in the aged nonhuman primate. Neurobiol Aging 14:627-629. CrossRef Medline

Rapp PR, Amaral DG (1989) Evidence for task-dependent memory dysfunction in the aged monkey. J Neurosci 9:3568-3576. CrossRef Medline

Rapp PR, Amaral DG (1991) Recognition memory deficits in a subpopulation of aged monkeys resemble the effects of medial temporal lobe damage. Neurobiol Aging 12:481-486. CrossRef Medline

Rapp PR, Morrison JH, Roberts JA (2003) Cyclic estrogen replacement improves cognitive function in aged ovariectomized rhesus monkeys. J Neurosci 23:5708-5714. CrossRef Medline 
Rawley JB, Constantinidis C (2009) Neural correlates of learning and working memory in the primate posterior parietal cortex. Neurobiol Learn Mem 91:129-138. CrossRef Medline

Rowe JB, Toni I, Josephs O, Frackowiak RS, Passingham RE (2000) The prefrontal cortex: response selection or maintenance within working memory? Science 288:1656-1660. CrossRef Medline

Salthouse TA, Babcock RL, Shaw RJ (1991) Effects of adult age on structural and operational capacities in working memory. Psychol Aging 6:118-127. CrossRef Medline

Sorra KE, Harris KM (2000) Overview on the structure, composition, function, development, and plasticity of hippocampal dendritic spines. Hippocampus 10:501-511. CrossRef Medline

Tsujimoto S, Postle BR (2012) The prefrontal cortex and oculomotor delayed response: a reconsideration of the "mnemonic scotoma." J Cogn Neurosci 24:627-635. CrossRef Medline

Voytko ML, Tinkler GP (2004) Cognitive function and its neural mechanisms in nonhuman primate models of aging, Alzheimer disease, and menopause. Front Biosci 9:1899-1914. CrossRef Medline
Wang M, Gamo NJ, Yang Y, Jin LE, Wang XJ, Laubach M, Mazer JA, Lee D, Arnsten AF (2011) Neuronal basis of age-related working memory decline. Nature 476:210-213. CrossRef Medline

Yang G, Pan F, Gan WB (2009) Stably maintained dendritic spines are associated with lifelong memories. Nature 462:920-924. CrossRef Medline

Yang N, Higuchi O, Ohashi K, Nagata K, Wada A, Kangawa K, Nishida E, Mizuno $\mathrm{K}$ (1998) Cofilin phosphorylation by LIM-kinase 1 and its role in racmediated actin reorganization. Nature 393:809-812. CrossRef Medline

Yang Y, Wang XB, Frerking M, Zhou Q (2008) Spine expansion and stabilization associated with long-term potentiation. J Neurosci 28:57405751. CrossRef Medline

Young ME, Ohm DT, Dumitriu D, Rapp PR, Morrison JH (2014) Differential effects of aging on dendritic spines in visual cortex and prefrontal cortex of the rhesus monkey. Neuroscience 274:33-43. CrossRef Medline

Zhou X, Zhu D, Qi XL, Lees CJ, Bennett AJ, Salinas E, Stanford TR, Constantinidis C (2013) Working memory performance and neural activity in prefrontal cortex of peripubertal monkeys. J Neurophysiol 110:26482660. CrossRef Medline 